\title{
Driver Eye Fixations and the Optimal Locations for Automobile Brake Lights
}

\author{
Michael Sivak, Larry S. Conn, and Paul L. Olson
}

\begin{abstract}
This study evaluated the distributions of driver eye fixations when following other vehicles. The aim was to describe the areas of the forward field of view that are most frequently fixated. Such information is important for selecting optimal locations for automobile brake lights: Brake lights that are closer to eye fixations are likely to result in shorter driver reaction times than brake lights farther away from the fixations. A head-mounted, corneal-reflection device was used to monitor eye fixations. The data were collected during daylight hours in slow-moving urban traffic. A total of 3,600 eye fixations were analyzed for three different lead cars. The results indicate that, under the conditions of this study, the eye fixations tended to concentrate on the rear-window of the lead car and not in the neighborhood of the standard low-mounted brake lights. The results provide a possible behavioral explanation for the accident reductions found with high-mounted brake lights in previous field studies. Furthermore, high-mounted brake lights located at the edges of the vehicle might be even closer to eye fixations than a center-high-mounted brake light.
\end{abstract}

Three recent accident studies have found that the frequency of ccrtain types of rearend collisions is reduced by about one half by using a single, center-high-mounted brakelight repeater (Malone, Kirkpatrick, Kohl, \& Baker, 1978; Reilly, Kurke, \& Buckenmeier, 1980; Rausch, Wong, \& Kirkpatrick, 1981). However, behavioral studies that investigated possible mechanisms responsible for the

Dr. Michael Sivak is a Research Scientist, Larry S. Conn is a Research Associate, and Dr. Paul L. Olson is a Research Scientist at the University of Michigan Transportation Research Institute, 2901 Baxter Road, Ann Arbor, MI 48109.

This study was supported by the Motor Vehicle Manufacturers Assuciation. accident reductions have produced mixed results. These studies cvaluated the frequency and delay of (a) brake responses (Allen Corp., 1978; Schmidt-Clausen, 1977; Sivak, Post, Olson, \& Donohue, 1981a, 1981b) and (b) vehicle speed-change responses (Sivak, Olson, \& Farmer, 1981).

The present study was designed to investigate the eye-fixation patterns of drivers in slow-speed, stop-and-go traffic typical of urban congestion. In constrast, the above-mentioned behavioral studies were run at higher speeds and in freer flowing traffic. An additional unique feature of this study was the absence of any high-mounted brake lights. The aim was to investigate the distribution of 
eye fixations when following cars without high-mounted brake lights, in order to describe the areas of the forward field of view that are most frequently fixated. The underlying assumption was that the closer brake lights are to eye fixations, the shorter reaction time a following driver will have. This effect of visual angle of stimuli on reaction time was recently documented by Cohen $(1983,1984)$ under actual driving conditions. Cohen denonstrated that the reaction time of drivers to small light stimuli mounted on the windshield is a monotonically increasing function of the visual angle between the eye fixation and the stimulus.

\section{METHOD}

\section{Design}

The eye-fixation measures were obtained from relatively "naive" subjects. The subjects were not told about the true purpose of the experiment. They were told that the reason for the equipment on their heads was to monitor the pupil size as a function of traffic conditions.

\section{Subjects}

Four males (ages 18, 19, 20, and 20) and two females (ages 24 and 26) were tested.

\section{Route}

The data for all six subjects were collected on the same route. The route was approximately 1.8 miles $(3 \mathrm{~km})$ long and included several downtown streets of Ann Arbor, a city with a population of approximately 110,000 . Throughout the route there is heavy vehicle, bicycle, and pedestrian traffic. The roadway on the route is mostly one lane in each direction, with on-street parking on both sides. The speed limit on the route is $25 \mathrm{mph}$ ( 40 $\mathrm{km} / \mathrm{h}$ ). The data were collected at speeds of approximately 3 to $25 \mathrm{mph}$ ( 5 to $40 \mathrm{~km} / \mathrm{h}$ ), with most collected at 3 to $12 \mathrm{mph}$ ( 5 to 20 $\mathrm{km} / \mathrm{h}$ ). The experiment was performed in daylight hours during days with no precipitation. The mean driver-to-rear lights following distance was $38.7 \mathrm{ft}(11.8 \mathrm{~m})$.

\section{Test Vehicles}

Three test vehicles were used: (a) a dark blue 1973 Dodge Polara, (b) a dark brown 1983 Chevrolet Caprice Classic Station Wagon, and (c) a dark red 1984 Chrysler Laser (Figure 1). The 1973 Dodge Polara was selected because similar models constituted a significant proportion of test vehicles in the first of the accident studies (Malone et al., 1978). The other two cars represented two contemporary vehicles with different arrangements of rear lights and different locations and sizes of rear windows. (This approach, of utilizing test vehicles for the lead vehicles, was selected because the interest was in analyzing many eye fixations in relation to a few selected lead vehicles.)

\section{Equipment}

Eye fixations were measured using an NAC Eye Mark Recorder, Model 4. Data were videotaped for later analysis.

During the experimental runs, subjects drove a 1980 Ford Country Squire station wagon. The recording equipment was installed in the back seat. The experimenter also rode in the back seat. He viewed a small black and white video monitor that displayed the videotaped scene and the eye mark.

\section{Procedure}

Two separate sessions were required for each subject. The first session was designed to familiarize the subject with the equipment and to screen out those who were bothered by the device or on whom the eye spot could not be found.

The actual data were collected during the second session. The instructions to the subjects indicated that they should follow the lead car while driving as they would normally. After the eye-mark recorder was fitted and calibrated, the subject drove about 3 miles $(5 \mathrm{~km})$ prior to arriving at the route where the data were recorded. The subject was not told that the data were collected only on a certain portion of the driven route.

Each subject drove the test portion of the route three times, following one of the three test vehicles each time. The order of the test vehicles was counterbalanced among the six subjects. 
FIGURE 1

PHOTOGRAPHS OF THE LEAD VEHICLES

(FROM TOP TO BOTTOM:

1973 DODGE POLARA,

1983 CHEVROLET CAPRICE CLASSIC

STATION WAGON, AND

1984 CHRYSLER LASER)
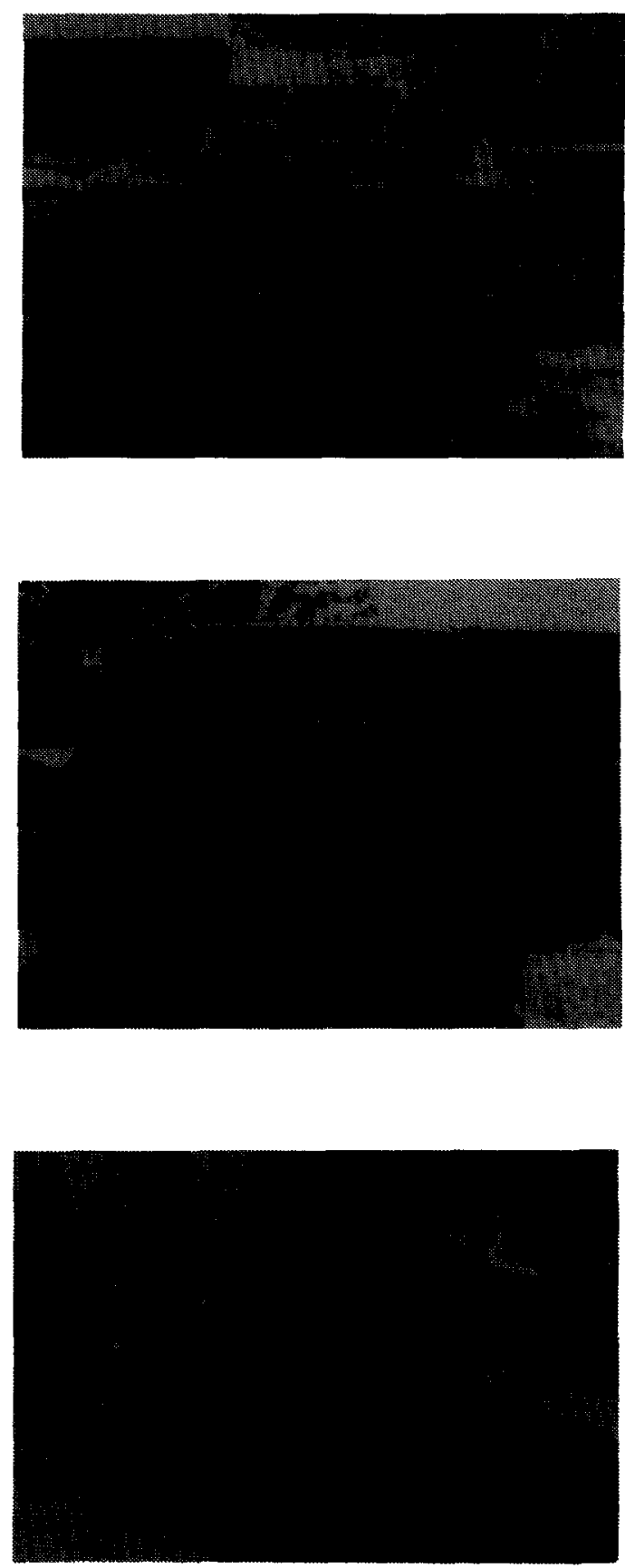

Frequent calibration checks were made throughout the route. If the equipment was found to be out of alignment, the previous portion of the route (from the previous alignment or from a sudden change in alignment) was not analyzed.

\section{Data Analysis}

The data were reduced on a frame-byframe basis. The coding system is illustrated in Figure 2. For each individual frame, the horizontal axis was defined as going through the center of the standard low-mounted brake lights, and the vertical axis as being identical to the centerline of the vehicle. (More precisely, the vertical axis was defined as being equidistant from the centers of both [left and right] standard brake lights. Because of the presence of a small lateral offset between the lead and the subject's vehicle on some trials, the planes running longitudinally through the centerlines of the two vehicles were not always identical. Furthermore, the view of the scene was taken from the driver's point of view, which is laterally offset from the centerline of the vehicle. Consequently, small nonsystematic horizontal errors were built into the coding system.)

The measures taken from each frame (see Figure 2) were as follows: (a) the horizontal coordinate of the fixation, $x_{F}$; (b) the vertical coordinate of the fixation, $y_{F}$; (c) the distance from the origin to the center of the standard low-mounted brake lamp, $x_{L}$; and (d) the distance from the origin to the hypothetical center-high-mounted brake lamp, $y_{c}$. These four measures were obtained by using a transparent millimeter-grid overlay. (The $x_{L}$ and $y_{C}$ measures were recorded in order (a) to compute the actual following distance, (b) to determine the locations of interest on the rear of the vehicle, and (c) to standardize the coordinates of the eye fixations.)

For each analyzed frame, the following four angular distances were computed from the fixation: (a) low - the distance to the nearer of the two standard low-mounted brake lights; (b) center - the distance to the hypothetical location of the center-high-mounted brake light; (c) dual - the distance to the nearer of the hypothetical dual-high-mounted brake lights; and (4) roof-the distance to the hypothetical location of the center-roof-mounted brake 
FIGURE 2

BASIC MEASURES DERIVED FROM EACH ANALYZED VIDEO FRAME

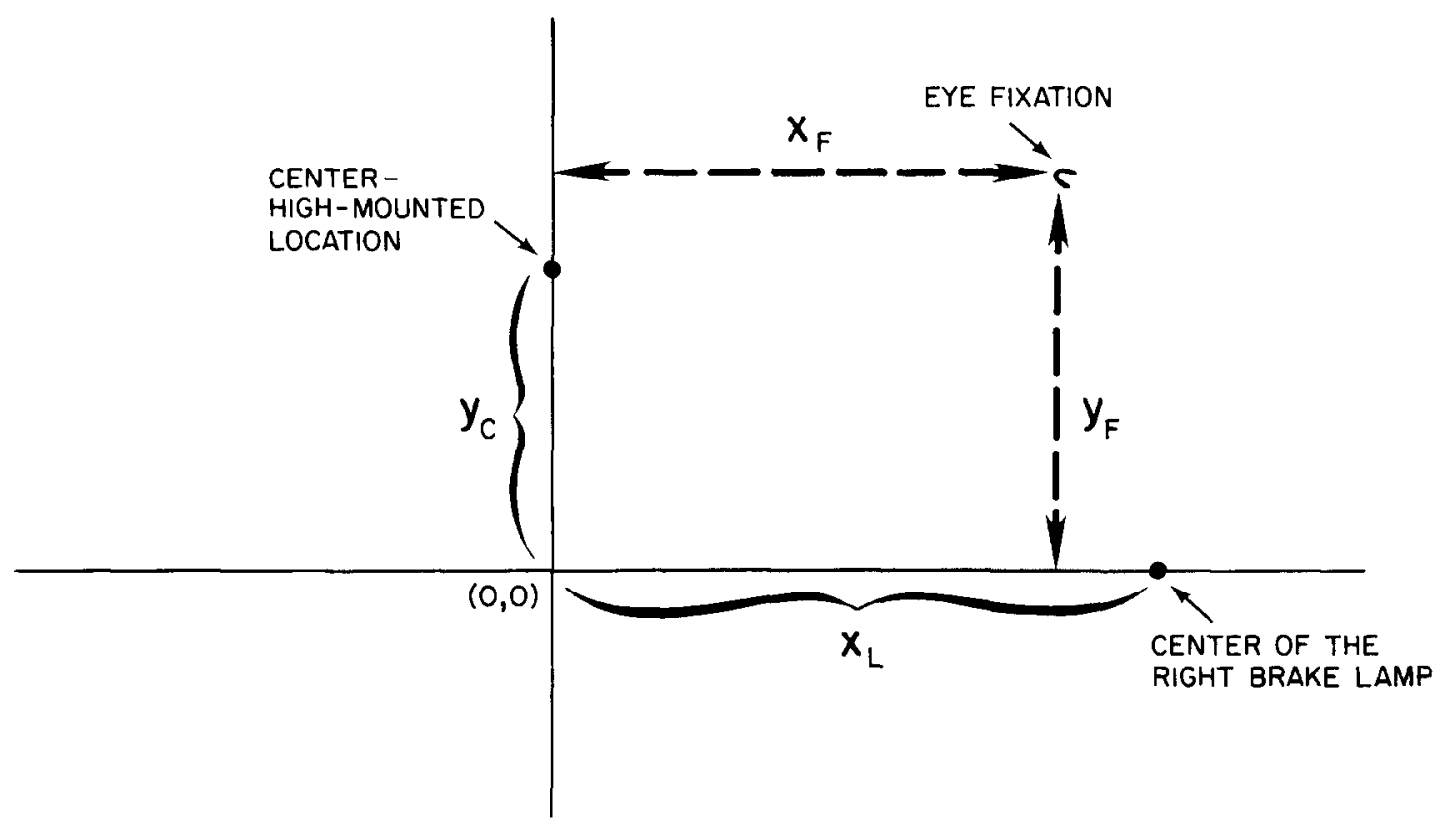

light. 'I'he coordinates for these locations of interest were derived for each analyzed frame from the corresponding $x_{L}$ and $y_{C}$ values and from the known geometric relations of the rear of each vehicle.

Additional analyses were performed on fixations for which (a) a location of interest was substantially distant (important because of a monotonic increase in reaction time as a function of visual angle), or (b) a location of interest fell on the fovea during a given eye fixation (important because the best photopic and mesopic vision occurs in this area of the visual field). Specifically, these analyses examined the frequencies of fixations that were more than $5^{\circ}$ or less than $1^{\circ}$ away from the locations of interest.

In order to plot the analyzed eye fixations on the same figure, a standardization to a common following distance was made. This standardization was performed as follows:

\section{Dodge Polara:}

$$
\begin{aligned}
& x_{\text {standardized }}=\left(40 / x_{L}\right) x_{F}, \text { and } \\
& y_{\text {standardized }}=\left(20 / y_{C}\right) y_{F}
\end{aligned}
$$

1983 Chevrolet Caprice Classic Station Wagon:

$$
\begin{aligned}
x_{\text {standardized }} & =\left(50 / x_{L}\right) x_{F}, \text { and } \\
y_{\text {standardized }} & =\left(20 / y_{C}\right) y_{F}
\end{aligned}
$$

\section{Chrysler Laser:}

$$
\begin{aligned}
& x_{\text {standardized }}=\left(30 / x_{L}\right) x_{F}, \text { and } \\
& y_{\text {standardized }}=\left(13 / y_{C}\right) y_{F}
\end{aligned}
$$

All of the above standardizing constants correspond to the measured values of $x_{L}$ and $y_{c}$, respectively, at an arbitrary following distance of $32.5 \mathrm{ft}(9.9 \mathrm{~m})$. Table 1 lists the coordinates for the location of interest for each vehicle at the same following distance $(32.5$ $\mathrm{ft}[9.9 \mathrm{~m}])$.

To spread the analyzed frames over a longer route distance, only every second eye fixation was analyzed, for a total of 200 fixations for each subject/vehicle combination.

\section{RESULTS}

Table 2 lists the mean angular distances for the unstandardized (raw) eye fixations to the locations of interest. The results of $t$ tests for 
TABLE 1

STANDARDIZED COORDINATES FOR TIIE LOCATIONS

OF INTEREST ON THE LEAD VEHICLES

\begin{tabular}{|c|c|c|c|c|c|c|}
\hline \multirow[b]{3}{*}{ LOCATION } & \multicolumn{6}{|c|}{ LEAD VEHICLE } \\
\hline & \multicolumn{2}{|c|}{$\begin{array}{l}1973 \text { Dodge } \\
\text { Polara }\end{array}$} & \multicolumn{2}{|c|}{$\begin{array}{l}1983 \text { Chevrolet } \\
\text { Caprice Classic } \\
\text { Station Wagon }\end{array}$} & \multicolumn{2}{|c|}{$\begin{array}{l}1984 \text { Chrysler } \\
\text { Laser }\end{array}$} \\
\hline & $x$ & $y$ & $x$ & $y$ & $x$ & $y$ \\
\hline Low & \pm 40 & 0 & \pm 50 & 0 & \pm 30 & 0 \\
\hline Center & 0 & 20 & 0 & 20 & 0 & 13 \\
\hline Dual & \pm 30 & 20 & \pm 32 & 20 & \pm 30 & 13 \\
\hline noof & 0 & 40 & 0 & 40 & 0 & 30 \\
\hline
\end{tabular}

the six pairs of fixation distances ( $t$ tests for paired samples [Dixon \& Massey, 1969]) are shown in Table 3. These two-tailed tests evaluated all pairwise differences between the four fixation distances. (Since six simultaneous $t$ tests were considered, the critical $\alpha$ level was adjusted by dividing the desired composite $\alpha$ level of 0.05 by six [Morrison, 1976]).

Table 4 presents the frequencies of fixations that were more than $5^{\circ}$ from the four locations of interest. Table 5 presents the fre- quencies of fixations that were less than $1^{\circ}$ from the locations of interest.

An example of a distribution of the stand ardized eye fixations is shown in Figure 3 for Subject 1 and the 1973 Dodge Polara. (The squares in Figure 3 correspond to the locations of interest on the rear of the vehicle. Only the lowest two squares correspond to the locations of actual rear lights on the vehicle; the other squares represent hypothetical locations only.) This distribution is typical of

TABLE 2

MEAN ANGULAR DISTANCES (IN DEGREES)

OF THE UNSTANDARDIZED EYE FIXATIONS

TO THE LOCATIONS OF INTEREST

\begin{tabular}{|c|c|c|c|c|c|c|}
\hline \multirow[b]{2}{*}{$\begin{array}{l}\text { LEAD VEHICLE } \\
\text { AND MEASURE }\end{array}$} & \multicolumn{6}{|c|}{ SUBJECT } \\
\hline & 1 & 2 & 3 & 4 & 5 & 6 \\
\hline \multicolumn{7}{|c|}{1973 Dodge Polara } \\
\hline Low & 4.2 & 4.4 & 3.6 & 4.0 & 4.7 & 3.8 \\
\hline Center & 2.9 & 3.1 & 3.8 & 3.3 & 4.7 & 3.7 \\
\hline Dual & 2.7 & 2.8 & 2.6 & 2.8 & 3.4 & 3.0 \\
\hline Roof & 3.3 & 3.3 & 3.7 & 3.4 & 4.6 & 3.9 \\
\hline \multicolumn{7}{|c|}{1983 Chevrolet Caprice } \\
\hline \multicolumn{7}{|c|}{ Classic Station Wagon } \\
\hline Low & 4.8 & 3.7 & 3.5 & 3.8 & 4.3 & 3.7 \\
\hline Center & 3.2 & 2.7 & 3.8 & 3.7 & 4.9 & 3.8 \\
\hline Dual & 3.2 & 2.5 & 2.9 & 3.0 & 3.5 & 2.9 \\
\hline Roof & 3.1 & 2.9 & 4.1 & 3.6 & 5.2 & 4.0 \\
\hline \multicolumn{7}{|c|}{1984 Chrysler Laser } \\
\hline Low & 3.2 & 4.0 & 4.1 & 4.1 & 3.8 & 4.0 \\
\hline Center & 3.2 & 3.3 & 3.8 & 4.0 & 4.2 & 4.2 \\
\hline Dual & 2.4 & 3.1 & 3.3 & 3.4 & 3.2 & 3.3 \\
\hline Roof & 3.0 & 2.8 & 3.6 & 3.8 & 4.2 & 4.0 \\
\hline
\end{tabular}


TABLE 3

SIGNIFICANTLY SHORTER FIXATION DISTANCES

FOUND IN PAIRWISE COMPARISONS OF MEAN ANGULAR DISTANCES ${ }^{\alpha}$

\begin{tabular}{|c|c|c|c|c|c|c|}
\hline \multirow{3}{*}{$\begin{array}{l}\text { LEAD VEHICLE AND } \\
\text { COMPARISON PAIR }\end{array}$} & \multicolumn{6}{|c|}{ SHORTER DISTANCE } \\
\hline & \multicolumn{6}{|c|}{ Subject } \\
\hline & 1 & 2 & 3 & 4 & 5 & 6 \\
\hline \multicolumn{7}{|l|}{1973 Dodge Polara } \\
\hline L vs. C & C & $\mathrm{C}$ & & $\mathrm{C}$ & & \\
\hline L vs. D & $\mathrm{D}$ & $\mathrm{D}$ & D & $\mathrm{D}$ & $\mathrm{D}$ & $\mathrm{D}$ \\
\hline L vs. R & $\mathrm{R}$ & $\mathbf{R}$ & & $\mathrm{R}$ & & \\
\hline C vs. D & & & D & $\mathrm{D}$ & $\mathrm{D}$ & $\mathrm{D}$ \\
\hline C vs. R & $\mathrm{C}$ & & & & & C \\
\hline D vs. $R$ & $\mathrm{D}$ & $\mathrm{D}$ & $\mathrm{D}$ & $\mathrm{D}$ & $\mathrm{D}$ & $\mathrm{D}$ \\
\hline \multicolumn{7}{|c|}{1983 Chevrolet Caprice } \\
\hline \multicolumn{7}{|c|}{ Classic Station Wagon } \\
\hline L vs. C & $\mathrm{C}$ & C & & & $\mathrm{L}$ & \\
\hline L vs. D & $\mathrm{D}$ & $\mathrm{D}$ & D & D & $\mathrm{D}$ & $\mathrm{D}$ \\
\hline L vs. R & $\mathrm{R}$ & $\mathbf{R}$ & $\mathrm{L}$ & & $\mathrm{L}$ & \\
\hline C vs. D & & & D & $\mathrm{D}$ & $\mathrm{D}$ & $\mathrm{D}$ \\
\hline C vs. R & & $\mathrm{C}$ & $\mathrm{C}$ & & $\mathrm{C}$ & \\
\hline D vs. $R$ & & $\mathrm{D}$ & $\mathrm{D}$ & $\mathrm{D}$ & $\mathrm{D}$ & $\mathrm{D}$ \\
\hline \multicolumn{7}{|l|}{1984 Chrysler Laser } \\
\hline L vs. C & & $\mathrm{C}$ & & & $\mathrm{L}$ & \\
\hline L vs. D & $\mathrm{D}$ & $\mathrm{D}$ & $\mathrm{D}$ & $\mathrm{D}$ & $\mathrm{D}$ & $\mathrm{D}$ \\
\hline L vs. $\mathrm{B}$ & & $\mathbf{R}$ & $\mathbf{R}$ & & $\mathrm{L}$ & \\
\hline C vs. D & $\mathrm{D}$ & & D & D & $\mathrm{D}$ & $\mathrm{D}$ \\
\hline C vs. R & $\mathrm{R}$ & $\mathrm{R}$ & $\mathbf{R}$ & & & $\mathrm{R}$ \\
\hline D vs. $R$ & $\mathrm{D}$ & & & D & $\mathrm{D}$ & $\mathrm{D}$ \\
\hline
\end{tabular}

Note $-\mathrm{L}=$ Low, $\mathrm{C}=$ Center, $\mathrm{D}=$ Dual, $\mathrm{R}=$ Roof.

${ }^{a}$ Mean angular fixation distances are listed in Table 2 .

the obtained 18 distributions ( 3 vehicles times 6 subjects) of the standardized eye fixations: The eye fixations tended to concentrate on the rear window area of the lead car, and there were very few fixations in the neighborhood of the standard low-mounted brake lights. The means and standard deviations of the horizontal and vertical coordinates of the standardized fixations are listed in Table 6.

\section{DISCUSSION}

Although there was considerable variation between subjects in the scatter of the eye fixations (see Table 6), two aspects were common to most of the distributions of the eye fixations. First, eye fixations tended to concentrate in the rear window area of the lead vehicle. Second, there were only a few eye fixations on or near the standard low-mounted brake lights.

Parametric evaluation of the locations of the eye fixations revealed the following:

\section{Dodge Polara}

The eye fixations were significantly closer to the center-high-mounted location than to either of the two standard low-mounted locations for three out of the six subjects. (For the other three subjects there was no significant difference.) Furthermore, for all six subjects the fixations within $1^{\circ}$ of visual angle were more numerous when measured from the center-high-mounted location, as opposed to the two standard low mounted locations. The analysis of the fixations that were more than $5^{\circ}$ distant did not indicate a clear advantage 
TABLE 4

FREQUENCY OF EYE FIXATIONS THAT WERE

MORE THAN $5^{\circ}$ FROM THE FOUR LOCATIONS OF INTEREST

\begin{tabular}{|c|c|c|c|c|c|c|}
\hline \multirow[b]{2}{*}{$\begin{array}{l}\text { LEAD VEHICLE } \\
\text { AND MEASURE }\end{array}$} & \multicolumn{6}{|c|}{ SUBJECT } \\
\hline & 1 & 2 & 3 & 4 & 5 & 6 \\
\hline \multicolumn{7}{|c|}{1973 Dodge Polara } \\
\hline Low & 52 & 65 & 37 & 57 & 77 & 44 \\
\hline Center & 27 & 33 & 46 & 42 & 77 & 43 \\
\hline Dual & 14 & 16 & 17 & 20 & 41 & 30 \\
\hline Roof & 29 & 39 & 45 & 46 & 66 & 49 \\
\hline \multicolumn{7}{|c|}{1983 Chevrolet Caprice } \\
\hline \multicolumn{7}{|c|}{ Classic Station Wagon } \\
\hline Low & 85 & 38 & 37 & 42 & 63 & 40 \\
\hline Center & 30 & 18 & 46 & 54 & 84 & 47 \\
\hline Dual & 22 & 15 & 25 & 25 & 36 & 26 \\
\hline Roof & 30 & 22 & 46 & 54 & 91 & 48 \\
\hline \multicolumn{7}{|c|}{1984 Chrysler Laser } \\
\hline Low & 23 & 53 & 59 & 54 & 43 & 52 \\
\hline Center & 27 & 27 & 50 & 53 & 59 & 61 \\
\hline Dual & 13 & 26 & 31 & 39 & 36 & 38 \\
\hline Roof & 28 & 18 & 38 & 49 & 58 & 57 \\
\hline
\end{tabular}

Note-These data are based on a total of 200 eye fixations for each subject/vehicle combination.

TABLE 5

FREQUENCY OF EYE FIXATIONS THAT WERE

LESS THAN $1^{\circ}$ FROM THE FOUR LOCATIONS OF INTEREST

\begin{tabular}{|c|c|c|c|c|c|c|}
\hline \multirow[b]{2}{*}{$\begin{array}{l}\text { LEAD VEHICLE } \\
\text { AND MEASURE }\end{array}$} & \multicolumn{6}{|c|}{ SUBJECT } \\
\hline & 1 & 2 & 3 & 4 & 5 & 6 \\
\hline \multicolumn{7}{|c|}{1973 Dodge Polara } \\
\hline Low & 2 & 1 & 8 & 4 & 4 & 5 \\
\hline Center & 22 & 27 & 12 & 18 & 5 & 18 \\
\hline Dual & 23 & 26 & 25 & 16 & 12 & 30 \\
\hline Roof & 15 & 20 & 14 & 25 & 7 & 11 \\
\hline \multicolumn{7}{|c|}{1983 Chevrolet Caprice } \\
\hline \multicolumn{7}{|c|}{ Classic Station Wagon } \\
\hline Low & 2 & 5 & 15 & 6 & 5 & 9 \\
\hline Center & 14 & 18 & 13 & 15 & 5 & 13 \\
\hline Dual & 14 & 34 & 25 & 16 & 12 & 20 \\
\hline Roof & 31 & 21 & 10 & 25 & 7 & 11 \\
\hline \multicolumn{7}{|c|}{1984 Chrysler Laser } \\
\hline Low & 7 & 7 & 4 & 8 & 9 & 2 \\
\hline Center & 11 & 11 & 13 & 17 & 15 & 16 \\
\hline Dual & 29 & 18 & 16 & 10 & 15 & 23 \\
\hline Roof & 27 & 22 & 12 & 16 & 10 & 17 \\
\hline
\end{tabular}

Note-These data are based on a total of 200 eye fixations for each subject/vehicle combination. 
FIGURE 3

DISTRIBUTION OF THE STANDARDIZED EYE FIXATIONS

FOR SUBJECT 1 AND 1973 DODGE POLARA

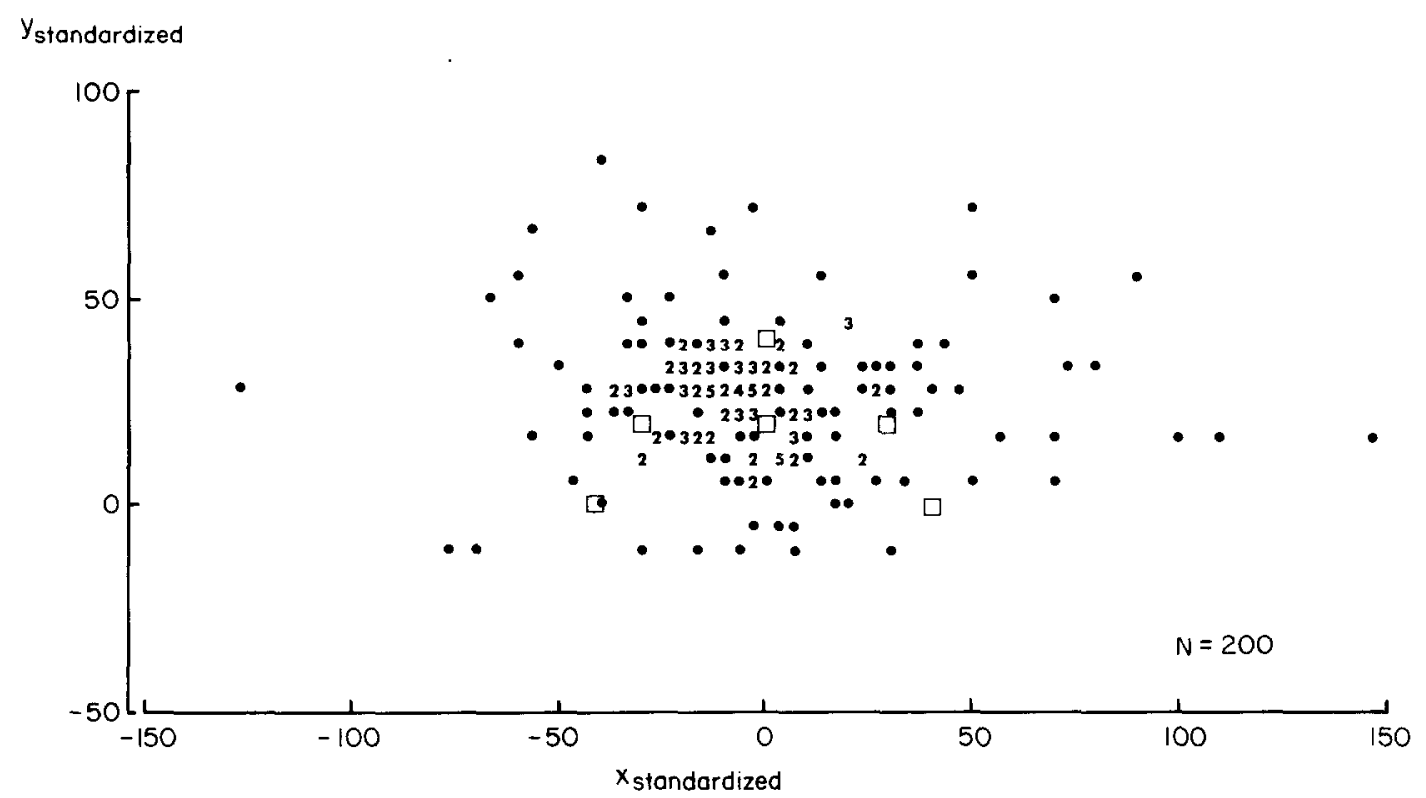

Note-A clot indicates a location of a single fixation, while a number indicates that more than one fixation fell on that location. The squares illustrate the locations of interest on the rear of the lead vehicle.

TABLE 6

COORDINATES OF THE MEAN OF THE STANDARDIZED EYE FIXATIONS AND THE CORRESPONDINC STANDARD DEVIATIONS

\begin{tabular}{|c|c|c|c|c|c|c|}
\hline \multirow{2}{*}{$\begin{array}{l}\text { LEAD VEHICLE } \\
\text { AND MEASURE }\end{array}$} & \multicolumn{6}{|c|}{ SUBJECT } \\
\hline & 1 & 2 & 3 & 4 & 5 & 6 \\
\hline \multicolumn{7}{|c|}{1973 Dodge Polara } \\
\hline$x$ & -2 & 1 & -11 & -12 & -1 & 4 \\
\hline$S D$ & 32 & 34 & 47 & 35 & 50 & 58 \\
\hline$y$ & 25 & 29 & 30 & 27 & 38 & 26 \\
\hline$S D$ & 16 & 18 & 21 & 25 & 23 & 24 \\
\hline \multicolumn{7}{|c|}{1983 Chevrolet Caprice } \\
\hline \multicolumn{7}{|c|}{ Classic Station Wagon } \\
\hline$x$ & 4 & -7 & -15 & 0 & 6 & -16 \\
\hline$S D$ & 37 & 31 & 53 & 60 & 57 & 59 \\
\hline$y$ & 33 & 28 & 22 & 33 & 22 & 28 \\
\hline$S D$ & 21 & 22 & 25 & 31 & 25 & 26 \\
\hline \multicolumn{7}{|c|}{1984 Chrysler Laser } \\
\hline$x$ & 18 & -1 & -6 & -2 & 7 & -7 \\
\hline$S D$ & 33 & 25 & 35 & 43 & 52 & 60 \\
\hline$y$ & 25 & 26 & 25 & 25 & 22 & 30 \\
\hline SD & 15 & 17 & 16 & 24 & 21 & 20 \\
\hline
\end{tabular}


for either the standard low-mounted or the center-high-mounted location.

Analogous comparisons all favored dualhigh-mounted locations over both the standard low-mounted and center-high-mounted locations. The roof-mounted location was favored over the standard low-mounted location, but not over the two locations at intermediate height (i.e., center-high-mounted and dual-high-mounted).

\section{Chevrolet Caprice \\ Classic Station Wagon and \\ 1984 Chrysler Laser}

The results of the pair-wise comparisons, and of fixations more than $5^{\circ}$ away, indicate no overall advantage of the center-high-mounted location over the standard low-mounted locations. As with the 1973 Dodge Polara, however, there were more eye fixations within $1^{\circ}$ of the center-high-mounted location than within $1^{\circ}$ of the two standard low-mounted locations.

In general, the obtained eye fixations favored (a) dual-high-mounted locations over both the standard low-mounted and centerhigh-mounted locations, and (b) (in terms of fixations within $1^{\circ}$ of the locations) the roofmounted location over the standard lowmounted location (but not over the centerand dual-high-mounted locations).

\section{CONCLUSIONS}

This study was designed to investigate the angular distance from potential locations of brake lights to eye fixations of following drivers. Obviously, the distance was measured in two dimensions, since the depth of the focus for each fixation was not known.

It is fully acknowledged that factors other than location, such as size, luminance, color, and uniqueness of the function, are significant determiners of the effectiveness of a brake light. When such factors are equal, however, it is likely that the distribution of angular separations between the location and driver eye fixations is a significant factor as well.

The present study has shown that the eye fixations under low-speed, stop-and-go traffic conditions were concentrated primarily in the area of the rear window. This finding is con- sistent with the hypothesis that drivers tended to look through the lead vehicle in an attempt to gain information from farther ahead. Consequently, angular separations of eye fixations from the locations on the rear window were generally shorter than from a standard location of brake lights. These findings may account for the reduction in rear-end collisions associated with a single, center-mounted brake light in field studies. (An improvernent in the congruence between eye fixation patterns and locations of brake lights for some drivers might be sufficient for accident reduction.) In the present study, however, the advantage in terms of the fixation distance of high-mounted locations was more consistent (across subjects and vehicles) for two outboard locations as opposed to a single central location.

From among the between-vehicle trends, the most important was that the advantage of the center-high-mounted over standard low-mounted locations was more pronounced for the 1973 Dodge Polara than for the other two test vehicles (1983 Chevrolet Caprice Classic Station Wagon and 1984 Chrysler Laser). Consequently, care has to be exercised when extrapolating results of accident (and behavioral) studies using given types of vehicles (of certain size, glass area, and location of standard brake lights) to the general population of vehicles.

\section{REFERENCES}

Allen Corporation of America. (1978, April). Field validation of taillights-Report on Phase 1: Pilot testing (Contract No. DOT-HS-7-01756). Alexandria, VA: Author.

Cohen, A. S. (1983). Einflussgrössen auf das nutzbare Sehfeld [Factors affecting the functional visual field]. Zürich: ETH, Institut für Verhaltenswissenschaft, Bericht zum Forschungsprojekt 8005 im Auftrag der Bundesanstalt für Strassenwesen.

Cohen, A. S. (1984). Latenzzeit der Reaktion im Strassenverkehr [Reaction time in road traffic]. Unfallund Sicherheitsforschung im Strassenverkehr, Heft 47, 131-135.

Dixon, W. J., \& Massey, F. J. (1969). Introduction to statistical analysis (3rd ed.). New York: McGraw-Hill. Malone, T. B., Kirkpatrick, M., Kohl, J. S., \& Baker, C. (1978, February). Field test evaluation of rear lighting systems (Contract No. DOT-HS-5-01228). Alexandria, VA: Fssex Corporation.

Morrison, D. L. (1976). Multivariate statistical methods (2nd ed.). New York: McGraw-Hill.

Rausch, A,, Wong, J., \& Kirkpatrick, M. (1981, April). 
A field test of two single center high mounted brake light systems. Washington, DC: Insurance Institute for Highway Safety.

Reilly, R. E., Kurke, D. S., \& Buckenmaier, C. C. (1980, May). Validation of the reduction of rear-end collisions by a high-mounted auxiliary stoplamp (Contract No. DOT-HS-7-01756). Alexandria, VA: Allen Corporation of America.

Schmidt-Clausen, H. J. (1977). Verbesserung des rückwärtigen Signalbildes auf Kraftfahrzeugen durch zusätzliche hochgesetzte Bremsleuchten [Improvement of the rear signal arrangment on motor vehicles by additional high-mounted brake lights]. ATZ Automobiltechnische Zeitschrift, 79, 505-508.
Sivak, M., Olson, P. L., \& Farmer, K. M. (1981). Highmounted brake lights and the behavior of following drivers (Report No. UM-HSRI-81-31). Ann Arbor, MI: Highway Safety Research Institute, The University of Michigan.

Sivak, M., Post, D. V., Olson, P. L., \& Donohue, R. J. (1981a). Automobile rear lights: Effects of the number, mounting height, and lateral position on reaction times of following drivers. Perceptual and Motor Skills, 52, 795-802.

Sivak, M., Post, D. V., Olson, P. L., \& Donohue, R. J. (1981b). Driver responses to high-mounted brake lights in actual traffic. Human Factors, 1981b, 23, $231-235$. 